\title{
Hereditary Breast and Ovarian Cancer - Current Clinical Guidelines in Germany
}

\author{
Bettina Kuschel Evelyn Hauenstein Marion Kiechle Alfons Meindl \\ Department of Obstetrics and Gynecology, Technical University of Munich, Germany
}

\section{Key Words}

Breast cancer, hereditary · Ovarian cancer - Genetic counseling · Surveillance program, intensified

\section{Summary}

About $5-10 \%$ of breast and ovarian cancer cases are due to germline mutations in known high-risk susceptibility genes such as BRCA1 or BRCA2. There is a substantial proportion of families with a positive family history for these cancers, in which no mutation in one of the known susceptibility genes can be identified. In Germany, since 2005 the cost of genetic counseling, genetic testing and intensified surveillance programs for families at risk is taken over by most of the national health insurance companies. This is limited to a period of 3 years and by contract bound to university centers already specialized in the field. This article presents the current clinical guidelines for genetic testing, genetic counseling and intensified surveillance programs in Germany.

\section{Genetic Background}

About $5-10 \%$ of all newly diagnosed breast cancers are due to hereditary causes. A familial risk can be found in the following groups:

- Familial breast and ovarian cancer is the most common syndrome. About $70-90 \%$ of hereditary breast cancer cases are due to this syndrome. Most patients show germline mutations of the BRCA1 (chromosome 17q21) or BRCA2 (13q12) genes. Most likely a mutation is found when there are very young patients with breast or ovarian cancer in the family, also the probability to detect a mutation increases with the number of affected family members [1].

\section{Schlüsselwörter}

Mammakarzinom, familiäres · Ovarialkarzinom .

Genetische Beratung · Screeningprogramm, intensives

\section{Zusammenfassung}

Etwa $5-10 \%$ aller Mamma- und Ovarialkarzinome sind durch Keimbahnmutationen in bekannten Hochrisikogenen wie BRCA1 oder BRCA2 zurückzuführen. Ein beachtlicher Anteil von Familien mit einer gehäuften Erkrankungsrate weist jedoch keine Mutationen in den bekannten Risikogenen auf. In Deutschland werden seit 2005 die Kosten für genetische Tests und intensivierte Früherkennungsuntersuchungen von den gesetzlichen Krankenkassen bezahlt. In diesem Artikel werden die aktuellen Leitlinien für genetische Beratung und Untersuchungen sowie für intensivierte Früherkennung zusammengefasst.

- Germline mutations in genes like p53 (17p13) are rare ( $<1 \%$ of inherited tumor syndromes). Li-Fraumeni families show different kinds of tumors (sarcomas, brain tumors, leukemias, breast, bronchial, prostate, pancreas, colon and ovarian cancer). Some of these tumors start in early childhood [1].

- Germline muations in genes like PTEN and ATM are also rare. Families with Cowden's disease present with benign and malignant tumors - such as adenomas, follicular thyroid cancer, polyps and adenocarcinomas of the gastrointestinal tract, ovarian cysts and cancers. Breast cancer is the most common malignant tumor in female mutation carriers [1].

\begin{tabular}{ll}
\hline KARGER & ( 2006 S. Karger Gm \\
$\begin{array}{l}\text { Fax +49 7614520714 } \\
\begin{array}{l}\text { E-mail Information@Karger.de } \\
\text { www.karger.com }\end{array}\end{array}$ & $\begin{array}{l}\text { Accessible online at: } \\
\text { www.karger.com/brc }\end{array}$ \\
\hline
\end{tabular}


Fig. 1. Cumulative disease risk for breast (•) and ovarian (ם) cancer in BRCA1 Ovarian cancer risk increases from age 40 and is much higher than in BRCA2 mutation carriers. mutation carriers.

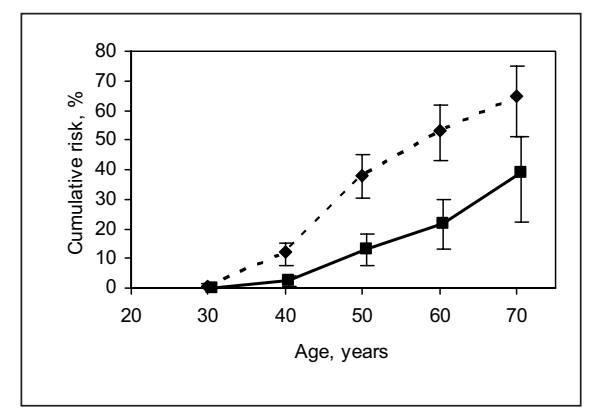

- Ataxia teleangiactasia (AT) is a complex disease. It is inherited in an autosomal-recessive pattern and affects children with cerebellar ataxia, teleangiektasia, immundeficiency and hypersensitivity for ionizing radiation. Homozygous individuals quite often do not reach adolescence. Epidemiological data show an increased breast cancer risk for heterozygous mutation carriers [2].

- Further susceptibility genes or gene clusters are suspected to be responsible for the remaining familial clustering of malignancy [3].

BRCA1- and BRCA2-associated breast cancer is the most common form of inherited breast cancer. Therefore most data are available for this kind of tumors and clinical recommendations are mainly based on knowledge about BRCA1/2 associated diseases. Clinical recommendations and decisions for hereditary tumor syndromes such as ATM or TP 53 have to be discussed individually.

\section{Disease Risks}

Estimates of disease penetrance for BRCA1 and BRCA2 mutation carriers vary enormously. The largest meta-analysis has been published in 2003 and compromises 22 studies with over 8,000 index cases [4]: The cumulative breast cancer risk (up to the age of 70 years) for BRCA1 mutation carriers is $65 \%$, for ovarian cancer the risk is $40 \%$ (fig. 1 ). BRCA2 mutation carriers have a risk of $45 \%$ to develop breast cancer and of $11 \%$ to develop ovarian cancer (fig. 2). BRCA1 mutation carriers are often diagnosed with breast cancer at a young (premenopausal) age. Ovarian cancer usually occurs later, when family planning has been concluded (after the age of 40 years).

\section{Male Mutation Carriers}

Sporadic breast cancer in male patients is very rare. It usually occurs in BRCA2 mutation carriers. Their risk is about $80-100 \times$ higher than in the normal population, they are affected with breast cancer up to the age of 80 years in about $7 \%$. About $15 \%$ of male breast cancer patients show a BRCA2 mutation. They also have a slightly increased risk for prostate, colon, pancreas and gastric cancer [5].

BRCA1 families show also a significantly increased risk for colon $(2 \times)$ and prostate $(2 \times)$ cancer [6]. It is discussed
Fig. 2. Cumulative disease risk for breast $(\bullet)$ and ovarian ( $\mathbf{})$ cancer in BRCA2 mutation carriers.

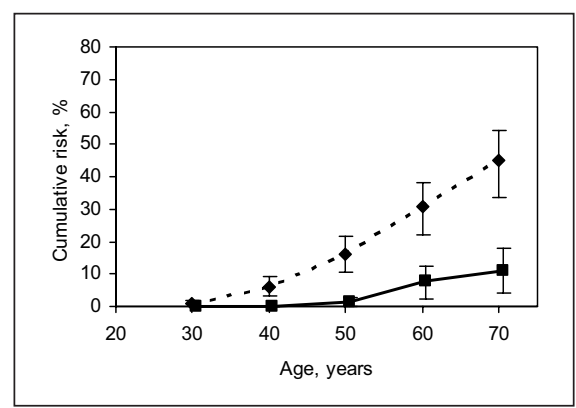

whether female mutation carriers have also increased risks for cervical and endometrial cancer and cancer of the fallopian tube $[7,8]$.

\section{Histopathology}

BRCA1 associated breast tumors seem to have different histological charateristics from BRCA2 associcated and other familial or sporadic breast cancers. Medullary histology occurs more often (10\%), tumors show high grading (G3) and are frequently found to be estrogen- and progesterone-receptor negative $[9,10]$. This has to be taken into account when intensified surveillance programs are established. Medullary breast cancer can look like benign fibroadenoma in imaging procedures and G3 tumors grow fast. Therefore, shorter screening intervals should be recommended. BRCA1 associated ovarian cancer seems to present with higher grading (G3) as well. They also seem to have more solid tumor components [11].

\section{Survival}

Overall survival in BRCA1 and BRCA2 mutation carriers is controversially discussed within the literature. Some studies show a difference in overall survival of mutation carriers, some do not. A tendency towards a shorter survival for BRCA1 mutation carriers is published quite frequently. In BRCA1 mutation carriers with ovarian cancer 5-year survival is $21 \%$, in BRCA2 mutation carriers it is $25 \%$ - both significantly lower than in patients with sporadic ovarian cancer [11]. But data are sparse, as yet there are no meta-analyses, therefore patients should not be counseled yet about these differences.

\section{Therapy}

There are very little data about differences in response to therapy. Therefore surgery and therapeutic procedures do not differ from treatment of sporadic disease. But studies are under way to test for therapeutic differences. 
Table 1. Intensified surveillance program offered to individuals with proven BRCA1/2 mutations, heterozygote risk $>20 \%{ }^{a}$, or lifetime breast cancer risk $>30 \%$ (up to age of 80 years $^{\text {a }}$ )

Frequent self-examination after expert instruction

6 Monthly: breast examination, breast ultrasound $(\geq 7.5 \mathrm{MHz})^{\mathrm{b}}$

12 Monthly: mammography ${ }^{\mathrm{c}}$, magnetic resonance tomography of breasts ${ }^{\mathrm{b}, \mathrm{d}}$

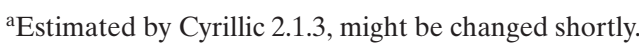

brom 25 years of age or 5 years before youngest family member diseased. cFrom 30 years of age, lifetime.

${ }^{\mathrm{d}} \mathrm{Up}$ to 55 years of age or when breast tissue sufficiently involuted for mammogram.

\section{Counseling and Genetic Testing in Germany}

It is strictly recommended that clinical, genetic, and psychooncologic counseling and genetic testing should be performed in multidisciplinary working groups located at universities. They should be members of the 'German Consortium for Hereditary Breast- and Ovarian Cancer' (addresses see addendum) that has been established in 1997 [12]. In the meantime these centers are organized nation-wide and connected. They are obliged to collect their data in a common database and are subject to frequent independent quality controls. Two reference centers of pathology (Bonn, Hanover) have been established to prove the histological data of affected family members and to work on questions concerning specific histological appearances, protein expression patterns etc. If families are counseled and tested in one of these centers, the cost of counseling and testing is taken over by most of the national health insurances. In 2005 they signed contracts with each center covering a period of 3 years. Special aims of these contracts are to continue the nationwide data collection, to increase knowledge of clinical behavior of hereditary tumors and to find out about the effectiveness (mobidity/mortality reduction) of intensified surveillance programs (table 1) for women at high risk. The intensified surveillance programs are restricted to those specialized centers. If an individual misses an appointment in the intensified surveillance program twice, the individual goes back into non-intensified normal screening programs by the national health insurances. The earlier practiced 6 monthly surveillance of ovaries has not been proven to be effective and is not recommended anymore.

\section{Genetic Counseling - Risk Estimation}

After contacting one of the centers (directly or transferred by a medical doctor), the women are interviewed on the telephone first. The purpose of the telephone interview is to find out about women/families at risk eligible for genetic testing and intensified surveillance programs (table 2). If families or single affected individuals fulfill the inclusion criteria for genetic testing, they are invited to clinical, genetic and - if needed or wanted - psychooncologic counseling. Before interdisciplinary counseling a psychological questionnaire is filled in by the individual in order to identify family members who might need additional psychological support.

Some centers might perform clinical and genetic counseling together in one session, others subsequently, however, expert standard is the basis and requested for each counselor.

\section{Inclusion Criteria}

A hereditary predisposition for breast and/or ovarian cancer should be considered for the following family types or single affected persons:

- at least 2 women with breast cancer, one of them diagnosed $<50$ years of age,

- one woman or family with both breast and ovarian cancer,

- one woman with premenopausal bilateral breast cancer,

- one woman with breast cancer diagnosed before the age of 35 years,

- a male individual with breast cancer.

An adequate counseling in an experienced center for hereditary breast and ovarian cancer should be initiated.

Genetic counseling includes:

- drawing a complete pedigree (over at least 3 generations),

- individual risk estimation (for gene carrier probability and lifetime breast cancer risks - equalized in all centers),

- tailored information about genetic background, gene penetrance, risk estimation, and sensitivity of genetic testing,

- information on consequences of genetic results for the individual and other family members,

- proof of reported affected family members by requesting original histology reports (tumor paraffin blocks are later requested by reference pathology departments),

- offering mutation screening in the two known BRCA genes if a family is able to prove (by medical documents) that the inclusion criteria mentioned above are fulfilled and/or the empiric probability of finding a BRCA1 or BRCA2 mutation is $\geq 10 \%$.

\section{Molecular Analysis}

By analyzing BRCA1/2 germline mutations it is possible to find out about individual cancer risks of members in BRCA1or BRCA2-positive families. Healthy individuals who did not inherit the familial mutation do not have increased cancer risks and do not need intensified surveillance programs (in families with autosomal-dominant mutations in BRCA1/2, ATM, PTEN, TP53 and HNPCC genes in about $50 \%$ of cases). If a healthy family member has inherited the mutation, intensified screening programs, prevention strategies and prophylactic surgery (mastectomy, oophorectomy) can be initiated.

Sometimes molecular analysis seems useful but cannot be done with sufficient power (e.g. when no affected family member is alive). Sometimes molecular analysis does not lead to a clear result (e.g. high-risk family with no mutation identified). Additionally the German guidelines for analyzing a genetic predisposition for cancer requests complete 'informed consent' of the tested person - that means if a family member 
Table 2. Empiric BRCA1/2 mutation frequencies for different risk profiles

\begin{tabular}{|c|c|c|}
\hline \multirow[t]{2}{*}{ Familial risk profile } & \multicolumn{2}{|c|}{ Empiric mutation frequency, \% } \\
\hline & $\begin{array}{l}\text { pathogenic } \\
\text { BRCA1/2 } \\
\text { mutations }\end{array}$ & $\begin{array}{l}\text { pathogenic including } \\
\text { unclassified variants }\end{array}$ \\
\hline \multicolumn{3}{|l|}{ A: 3 or more female relatives with breast cancer, at least 2 of them diseased prior to 50 years } \\
\hline B: 3 or more female relatives with breast cancer, one diseased before the age of 50 years & 9.40 & 17.90 \\
\hline C: 2 female relatives with breast cancer diseased before 50 years of age & 22.80 & 33.60 \\
\hline D: 2 female relatives with breast cancer, 1 of them diseased before 50 years of age & 10.30 & 17.30 \\
\hline E: at least 1 relative with breast cancer and 1 with ovarian cancer & 43.60 & 51.50 \\
\hline F: at least 2 family members with ovarian cancer & 41.90 & 55.80 \\
\hline G: 1 woman with breast cancer diseased before the age of 35 years & 19.10 & 23.50 \\
\hline I: 1 woman with bilateral breast cancer, first disease before the age of 40 years & 21.40 & 35.70 \\
\hline $\mathrm{J}: 1$ woman with breast and ovarian cancer & 44.00 & 48.00 \\
\hline
\end{tabular}

Data from the German consortium for hereditary breast- and ovarian cancer, evaluated in 2,471 family analyses.

does not want to be tested the decision of that member has to be accepted by the family and medical staff. These decisions can become very complex and lead to ethical conflicts within families as well as between geneticists, medical doctors and psychologists [13].

\section{Clinical Counseling}

Clinical counseling includes taking a complete medical history, explaining the individual disease risks, especially in respect to mutation carrier risks and associated disease risks (contralateral breast cancer, associated and secondary tumors) and discussion of family planning aspects.

\section{Special Aspects of Hormonal Contraception/Hormone Replacement Therapies}

There are sufficient data about the protective effect of premenopausally administered oral contraceptives and the risk for ovarian cancer in the general population [14]. A retrospective analysis of oral contraceptives in BRCA1 and BRCA2 mutation carriers also shows a protective effect, dependent on the duration of use: Use of oral contraceptives for 6 and more years leads to a risk reduction of $60 \%$ [15]. Recently, those results were confirmed by a British research group [16]. However, in view of the small number of cases, it seems too early to recommend oral contraceptives as prevention strategy for hereditary ovarian cancer. There is also a study with contrasting data [17]. So far no prospective data have been published. Furthermore, especially in hereditary breast and ovarian cancer syndrome, the use of oral contraceptives possibly increases the risk for breast cancer [18]. Generally it is recommended to use a low dosage of an estrogen/progesterone combination.

\section{Chemoprevention}

Chemoprevention for breast cancer has been examined by modulating endocrine influences on breast tissue. Since the 1990s, data exist concerning the use of tamoxifen in women with an increased risk of developing breast cancer. In analogy to data for contralateral breast cancer in adjuvant therapy strategies, a risk reduction of $50 \%$ was expected. However, studies did not show clear results: In the placebo controlled NSABP-P1 trial, a risk reduction of almost $50 \%$ could only be shown for estrogen receptor-positive cancers [19]. A risk reduction of $32 \%$ in patients at high risk could be shown by the International Breast Cancer Intervention Study (IBIS-I). In contrast, neither a British [20] nor an Italian trial [21] could show a risk reduction. Concerning the preventive effect of tamoxifen especially for BRCA mutation carriers only few data are available from retrospective subgroup analyses with a small number of cases, with different results. Even if a reduced risk for contralateral breast cancer in mutation carriers could be shown [22] and the adjuvant use in hormone receptor positive cancers in these patients is not to be doubted, a general recommendation for tamoxifen use cannot be given. The same is true for the use of selective estrogen receptor modulators (SERMs) like raloxifene, even if data here are more convincing: In an osteoporosis study (MORE), a significantly lower incidence of breast cancers could be shown [23]. In the P2:STAR trial, the use of raloxifene compared to tamoxifen in primary prevention, regarding effectiveness and toxicity, was examined. First results are to be expected soon. Further studies examine the use of aromatase inhibitors (IBIS II) [24], gosereline and the bisphosphonate ibandronate (GISS) [20], and the use of retinoid acids, which are discussed as a possible substance class for chemoprevention since the 1970s [25]. So far, results from prospective studies are not sufficient to draw conclusions. Therefore a definitive recommendation for chemoprevention in women with increased breast and ovarian cancer risk cannot be given at the moment. Nonetheless, there is an urgent need for prospective study protocols. 
Table 3. Prophylactic surgery offered to women with proven BRCA1/2 mutations

\section{Bilateral mastectomy* \\ - From age of 25 years (or 5 years before youngest family member was affected)}

Bilateral salpingo-oophorectomy*

- From age of 40 years (or 5 years before youngest family member was affected)

* It is strictly recommended to send removed organs directly to reference pathology departments.

\section{Intensified Surveillance Programs}

Based on individual risk estimations (see genetic counseling), an intensified surveillance program is offered (table 1). It has to be performed within the center. New data on the rank of magnetic resonance imaging (MRI) in women with a familial cancer risk are now available. MRI was shown to be the most sensitive method for the detection of malignomas and pre-malignant forms of disease [26]. Whereas MRI had a sensitivity of $75-95 \%$ in all studies so far, mammography could only reach detection levels of $30-70 \%$. This underlines the importance of MRI as a useful and necessary method for sufficient surveillance of high-risk patient collectives [13]. A Canadian study showed that the combination of 4 screening modalities (breast examination, sonography, mammography, and MRI) resulted in a sensitivity of $95 \%$, whereas the use of mammography and breast examination alone showed a sensitivity of only $45 \%$ [26].

\section{Prophylactic Surgery}

Alternatively, risk reduction of prophylactic surgery is discussed (mastectomy, bilateral salpingo-oophorectomy) (table 3). So far, prophylactic surgery is the only evidence-based procedure for risk reduction in mutation carriers and women with familial risk without proof of a known mutation [27-29]. According to international consensus, the common term 'prophylactic mastectomy' is to be substituted by 'bilateral or bothsided risk-reducing mastectomy (BRMx)'. The existing data originate from retrospective studies and small case group analyses. Hartmann et al. [30] could show a risk reduction of over $90 \%$ for more than 600 women with bilateral subcutaneous mastectomy or total mastectomy. In none of the $26 \mathrm{mu}-$ tation carriers retrospectively identified in this collective, breast cancer occurred during a follow-up period of more than 13 years [31]. First data of prospective studies are now available [29]. A Dutch study examined 76 healthy mutation carriers with BRMx and 63 carriers who did not wish to undergo surgical procedures: In a short follow-up time, 8 cancers occurred in the control group, whereas none of the patients having undergone BRMx suffered from breast cancer. The risk for contralateral breast cancer in mutation carriers is approximately $40 \%$ in 10 years, according to very inhomogeneous data [24].
A Cochrane analysis of all existing studies on BRMx published in October 2004 could not give a definite statement for this sub-collective. Also, for breast conserving therapy, there are only data gained in small case studies. Recently published retrospective analyses could not identify familial cancer as an independent risk factor for a local recurrence [27]. Women who already developed breast cancer opt for risk-reducing surgical procedures more often than healthy individuals.

Retrospective analyses show that prophylactic oophorectomy decreases the risk for ovarian cancer in women with a familial background by up to $96 \%[28,29]$. Evidence also exists that even tubal ligation alone reduces the risk for ovarian cancer in BRCA1 carriers [32]. Because cancer of the fallopian tube seems to be more frequent in BRCA1 carriers [7], prophylactic salpingo-oophorectomy (PBSO) is recommended in contrast to oophorectomy alone. The procedure can be performed by laparoscopy. Due to the risk of extraovarian peritoneal carcinosis (about $3 \%$ following prophylactic oophorectomy), the infundibulo-pelvicular ligament should be dissected and partly resected during laparoscopy. The whole peritoneal cavity should be examined, including peritoneal lavage and multiple biopsies [12].

Three large studies on the effect of PBSO on breast and ovarian cancer risk in BRCA1/2 mutation carriers exist. A retrospective cohort study on 43 BRCA1 mutation carriers having undergone prophylactic oophorectomy versus 79 mutation carriers who did not have surgery showed that breast cancer risk is reduced by up to $50 \%$. This result was not influenced by use of hormone replacement therapy [28]. A following study showed that in $2 \%$ of mutation carriers (6/259) a stage I ovarian cancer could be found at the time of prophylactic surgery. In two other women from the group having undergone surgery, an extraovarial (peritoneal) ovarian cancer was diagnosed in the later follow-up. Out of 292 control persons without surgery, $20 \%$ developed an ovarian cancer during a follow-up of 8 years. Furthermore, breast cancer risk could be decreased by up to $50 \%$ in women who underwent prophylactic oophorectomy between 35 and 50 years of age [33]. Kauff et al. [29] could confirm these data by a prospective cohort study ( $\mathrm{n}=72$ women with intensified surveillance versus $\mathrm{n}=98$ with PBSO).

\section{Quality Control}

Since 2005 (contracts with health insurance companies) a strict quality control is requested by experts and health insurance companies. Counseling has to be done on expert level, each center has to perform at least 50 interdisciplinary counseling sessions on hereditary breast and ovarian cancer per year. A period of at least 4 weeks between first counseling and induction of predictive testing is recommended. A letter summarizing the interdisciplinary counseling and clinical recommendations has to be sent within 4 weeks to each individual. 
Genetic testing is only performed in laboratories with at least 50 complete BRCA1/2 analyses per year. Analysis time should not exceed 4 months. Apart from these strict guidelines, equalized and controlled documentation is obligatory for all disciplines (geneticists, gynecologists, psycho-oncologists, radiologists, pathologists).

\section{Addendum}

'German Consortium for Hereditary Breast and Ovarian Cancer', addresses: Berlin

Max-Delbrück-Centrum für Molekulare Medizin, Bereich Tumorgenetik Robert-Rössle-Straße 10, 13122 Berlin

Zentrumssprecher: Prof. Dr. Siegfried Schemeck

Termine für Betroffene: Tel. 030 4505-66662

Düsseldorf

Frauenklinik der Medizinischen Einrichtungen der Universität Düsseldorf Moorenstraße 5, 40225 Düsseldor

Zentrumssprecherin: Dr. Carolin Nestle-Krämling

Termine für Betroffene: Tel. 0211 811-7503 oder -7540

Dresden

Medizinische Fakultät der TU Dresden

Klinik und Poliklinik für Frauenheilkunde und Geburtshilfe

Fetscherstraße 74, 01307 Dresden

Zentrumssprecher: Prof. Dr. Wolfgang Distler

Termine für Betroffene: Tel. 0351 458-2864

Hannover

MHH - Institut für Zell- und Molekularpathologie

Carl-Neuberg-Str. 1, 30625 Hannover

Zentrumssprecherin: Prof. Dr. Brigitte Schlegelberger

Termine für Betroffene: Tel.: 0511532 4522-20

Institut für Humangenetik der Universität Heidelberg

Im Neuenheimer Feld 328, 69120 Heidelberg

Zentrumssprecher: Prof. Dr. Claus R. Bartram

Termine für Betroffene: Tel. 06221565087

\section{Kie}

Universitäts-Frauenklinik Kiel

Michaelistraße 16, 24105 Kiel

Zentrumssprecher: Prof. Dr. Walter Jonat

Termine für Betroffene: Tel. 0431 59720-71 oder -77

Köln/Bonn

Universitäts-Frauenklinik Köln

Kerpener Straße 34, 50931 Köln

Termine für Betroffene: Tel. 0221 478-4900

Universitäts-Frauenklinik Bonn

Siegmund-Freud-Straße 25, 53127 Bonn

Zentrumssprecherin: Prof. Dr. Rita Schmutzler

Termine für Betroffene: Tel. 0228 287-5450

Leipzig

Institut für Humangenetik der Universität Leipzig

Philipp-Rosenthal-Straße 55, 04103 Leipzig

Zentrumssprecherin: Prof. Dr. Ursula Froster

Termine für Betroffene: Tel. 0341 972-3800

\section{München}

Universitäts-Frauenklinik im Klinikum Großhadern

Marchioninistraße 25, 81377 München

Termine für Betroffene: Tel. 089 7095-7571

Universitäts-Frauenklinik am Klinikum rechts der Isar

Ismaninger Straße 22, 81675 München

Zentrumssprecher: Prof. Dr. Alfons Meindl

Termine für Betroffene: Tel. 089 4140-2446 oder -7406

Münster

Institut für Humangenetik der Universität Münster

Vesatiusweg 12-14, 48149 Münster

Zentrumssprecher: Prof. Dr. Jürgen Horst

Termine für Betroffene: Tel. 0251 835-5413

Ulm

Frauenklinik und Poliklinik der Universität Ulm

Prittwitzstraße 43, 89075 Ulm

Zentrumssprecher: Prof. Dr. Rolf Kreienberg

Termine für Betroffene: Tel. 0731 5002-7606

Würzburg

Institut für Humangenetik der Universität Würzburg

Am Hubland, 97074 Würzburg

Zentrumssprecher: Prof. Dr. Bernhard Weber

\section{References}

1 Kuschel B, Kochli OR, Niederacher D, Muller H, Beckmann MW: Hereditary cancer syndromes in gynecology: what the practitioner needs to know Schweiz Med Wochenschr 2000;130(10):362-375.

2 Thompson D, Duedal S, Kirner J, McGuffog L, Last J, Reiman A, Byrd P, Taylor M, Easton DF: Cancer risks and mortality in heterozygous ATM mutation carriers. J Natl Cancer Inst 2005;97(11):813-822.

$\checkmark 3$ Antoniou AC, Pharoah PD, McMullan G, Day NE, Stratton MR, Peto J, Ponder BJ, Easton DF: A comprehensive model for familial breast cancer incorporating BRCA1, BRCA2 and other genes. Br J Cancer 2002;86(1):76-83.

4 Antoniou A, Pharoah PD, Narod S, Risch HA Eyfjord JE, Hopper JL, Loman N, Olsson $\mathrm{H}$, Johannsson O, Borg A et al.: Average risks of breast and ovarian cancer associated with BRCA1 or BRCA2 mutations detected in case Series unselected for family history: a combined analysis of 22 studies. Am J Hum Genet 2003;72(5):1117-1130.

5 Liede A, Karlan BY, Narod SA: Cancer risks for male carriers of germline mutations in BRCA1 or BRCA2: a review of the literature. J Clin Oncol 2004;22(4):735-742.
6 Ford D, Easton DF, Bishop DT, Narod SA, Goldgar DE, Breast Cancer Linkage Consortium: Risks of cancer in BRCA1 mutation carriers. Lancet 1994:343:692-695.

7 Thompson D, Easton DF: Cancer Incidence in BRCA1 mutation carriers. J Natl Cancer Inst 2002; 94(18):1358-1365.

8 Ford D, Easton DF, Peto J: Estimates of the gene frequency of BRCA1 and its contribution to breast and ovarian cancer incidence. Am J Hum Genet 1995;57(6):1457-1462.

9 Lakhani SR, Jacquemier J, Sloane JP, Gusterson BA, Anderson TJ, van de Vijver MJ, Farid LM, Venter D, Antoniou A, Storfer Isser A et al.: Multifactorial analysis of differences between sporadic breast cancers and cancers involving BRCA1 and BRCA2 mutations. J Natl Cancer Inst 1998;90(15): 1138-1145.

10 Lakhani SR, Van De Vijver MJ, Jacquemier J, Anderson TJ, Osin PP, McGuffog L, Easton DF: The Pathology of Familial Breast Cancer: Predictive value of immunohistochemical markers estrogen receptor, progesterone receptor, HER-2, and p53 in patients with mutations in BRCA1 and BRCA2. J Clin Oncol 2002;20(9):2310-2318
11 Pharoah PDP, Easton DF, Stockton DL, Gayther SA, Ponder BAJ: Survival in familial, BRCA1 and BRCA2 associated epithelial ovarian cancer. Cancer Res 1999:59:868-871.

12 Schmutzler RK, Beckmann MW, Kiechle M: Prävention: Familiäres Mamma- und Ovarialkarzinom. Deutsches Ärzteblatt 2002;99(20):A-1372.

13 Kuschel B, Kiechle M: Stellenwert der prädiktiven genetischen Diagnostik bei Tumorerkrankungen. Klinische Relevanz und ethische Problemfälle. Onkologe 2003;9(2):146-152.

14 Whittemore AS, Harris R, Itnyre J: Characteristics relating to ovarian cancer risk: collaborative analysis of 12 US case-control studies. II. Invasive epithelial ovarian cancers in white women. Collaborative Ovarian Cancer Group. Am J Epidemiol 1992; 136(10):1184-1203.

15 Narod SA, Risch H, Moslehi R, Dorum A, Neuhausen S, Olsson H, Provencher D, Radice P, Evans G, Bishop S et al.: Oral contraceptives and the risk of hereditary ovarian cancer. N Engl J Med 1998;339(7):424-428. 
16 Whittemore AS, Balise RR, Pharoah PD, Dicioccio RA, Oakley-Girvan I, Ramus SJ, Daly M, Usinowicz MB, Garlinghouse-Jones K, Ponder BA et al.: Oral contraceptive use and ovarian cancer risk among carriers of BRCA1 or BRCA2 mutations. Br J Cancer 2004;91(11):1911-1915.

17 Modan B, Hartge P, Hirsh-Yechezkel G, Chetrit A Lubin F, Beller U, Ben-Baruch G, Fishman A, Menczer J, Ebbers SM et al.: Parity, oral contraceptives, and the risk of ovarian cancer among carriers and noncarriers of a BRCA1 or BRCA2 mutation. N Engl J Med 2001;345(4):235-240.

18 Grabrick DM, Hartmann LC, Cerhan JR, Vierkant RA, Therneau TM, Vachon CM, Olson JE, Couch FJ, Anderson KE, Pankratz VS et al.: Risk of breast cancer with oral contraceptive use in women with a family history of breast cancer. JAMA 2000;284(14):1791-1798.

19 Fisher B, Costantino JP, Wickerham DL, Redmond CK, Kavanah M, Cronin WM, Vogel V, Robidoux A, Dimitrov N, Atkins J et al.: Tamoxifen for prevention of breast cancer: report of the National Surgical Adjuvant Breast and Bowel Project P-1 Study. J Natl Cancer Inst 1998;90(18):1371-1388.

20 Paepke S, von Minckwitz G, Kaufmann M, Schwarz-Boeger U, Jacobs VR, Aigner M, Pfeifer K, Ehmer M, Huttner C, Blohmer JU, Kiechle M: Chemoprevention of breast cancer: a literature review and report on the current status in Germany. Zentralbl Gynakol 2003;125(9):338-345.

21 Veronesi U, Maisonneuve P, Costa A, Sacchini V, Maltoni C, Robertson C, Rotmensz N, Boyle P: Prevention of breast cancer with tamoxifen: preliminary findings from the Italian randomised trial among hysterectomised women. Italian Tamoxifen Prevention Study. Lancet 1998;352(9122):93-97.

22 Narod SA, Brunet JS, Ghadirian P, Robson M, Heimdal K, Neuhausen SL, Stoppa-Lyonnet D, Lerman C, Pasini B, de los Rios P et al.: Tamoxifen and risk of contralateral breast cancer in BRCA1 and BRCA2 mutation carriers: a case-control study. Hereditary Breast Cancer Clinical Study Group. Lancet 2000;356(9245):1876-1881.

23 Cummings SR, Eckert S, Krueger KA, Grady D, Powles TJ, Cauley JA, Norton L, Nickelsen T, Bjarnason $\mathrm{NH}$, Morrow $\mathrm{M}$ et al.: The effect of raloxifene on risk of breast cancer in postmenopausal women: results from the MORE randomized trial. JAMA 1999;281(23):2189-2197.

24 Metcalfe K, Lynch HT, Ghadirian P, Tung N, Olivotto I, Warner E, Olopade OI, Eisen A, Weber B, McLennan J et al.: Contralateral breast cancer in BRCA1 and BRCA2 mutation carriers. J Clin Oncol 2004;22(12):2328-2335.

25 Veronesi U, De Palo G, Marubini E, Costa A, Formelli F, Mariani L, Decensi A, Camerini T, Del Turco MR, Di Mauro MG et al.: Randomized trial of fenretinide to prevent second breast malignancy in women with early breast cancer. J Natl Cancer Inst 1999;91(21):1847-1856.

26 Warner E, Plewes DB, Hill KA, Causer PA, Zubovits JT, Jong RA, Cutrara MR, DeBoer G, Yaffe MJ, Messner SJ et al.: Surveillance of BRCA1 and BRCA2 mutation carriers with magnetic resonance imaging, ultrasound, mammography, and clinical breast examination. JAMA 2004;292(11):1317-1325

27 Seynaeve C, Verhoog LC, van de Bosch LM, van Geel AN, Menke-Pluymers M, Meijers-Heijboer EJ, van den Ouweland AM, Wagner A, Creutzberg $\mathrm{CL}$, Niermeijer MF et al.: Ipsilateral breast tumour recurrence in hereditary breast cancer following breast-conserving therapy. Eur J Cancer 2004;40 (8):1150-1158.
28 Rebbeck TR, Levin AM, Eisen A, Snyder C, Watson $\mathrm{P}$, Cannon-Albright $\mathrm{L}$, Isaacs $\mathrm{C}$, Olopade $\mathrm{O}$, Garber JE, Godwin AK et al.: Breast cancer risk after bilateral prophylactic oophorectomy in BRCA1 mutation carriers. J Natl Cancer Inst 1999; 91(17):1475-1479.

29 Kauff ND, Satagopan JM, Robson ME, Scheuer L, Hensley M, Hudis CA, Ellis NA, Boyd J, Borgen PI, Barakat RR et al.: Risk-reducing salpingooophorectomy in women with a BRCA1 or BRCA2 mutation. N Engl J Med 2002;346(21): 1609-1615.

30 Hartmann LC, Schaid DJ, Woods JE, Crotty TP, Myers JL, Arnold PG, Petty PM, Sellers TA, Johnson JL, McDonnell SK et al.: Efficacy of bilateral prophylactic mastectomy in women with a family history of breast cancer. N Engl J Med 1999;340 (2):77-84.

31 Hartmann LC, Sellers TA, Schaid DJ, Frank TS, Soderberg CL, Sitta DL, Frost MH, Grant CS, Donohue JH, Woods JE et al.: Efficacy of bilateral prophylactic mastectomy in BRCA1 and BRCA2 gene mutation carriers. J Natl Cancer Inst 2001;93 (21):1633-1637.

32 Narod SA, Sun P, Ghadirian P, Lynch H, Isaacs C, Garber J, Weber B, Karlan B, Fishman D, Rosen B et al.: Tubal ligation and risk of ovarian cancer in carriers of BRCA1 or BRCA2 mutations: a casecontrol study. Lancet 2001;357(9267):1467-1470.

33 Rebbeck TR, Lynch HT, Neuhausen SL, Narod SA, Van't Veer L, Garber JE, Evans G, Isaacs C, Daly MB, Matloff E et al.: Prophylactic oophorectomy in carriers of BRCA1 or BRCA2 mutations. N Engl J Med 2002;346(21):1616-1622. 